\title{
Screening of Selected Rice Genotypes for Their Resistance against Brown Planthopper, Nilaparvata lugens (Stal)
}

\author{
M. Udayasree*, P. Rajanikanth, N.R.G. Varma and M. Sreedhar \\ Professor Jayashankar Telangana State Agricultural University, Rajendranagar, \\ Hyderabad, Telangana, India \\ *Corresponding author
}

\section{A B S T R A C T}

\section{Keywords \\ Rice genotypes, \\ Resistance, Brown \\ planthopper, Nilaparvata \\ lugens (Stal) \\ Article Info \\ Accepted: \\ 26 October 2018 \\ Available Online: \\ 10 November 2018}

The development of biotypes and existence of variability in Brown planthopper population always demands for the identification of new sources of resistance from time to time. However, the presence of desirable quality and yield traits in the genotypes along with source of resistance to BPH will be an added advantage. Screening was carried out with 39such promising rice genotypes and three checks following standard seed box technique. The test revealed 17 genotypes to be moderately resistant with damage score ranging between 3.6 -5.0. Among 17 genotypes, KNM 2305 and RNR 21571 recorded lowest damage score of 3.6. Further investigations on presence of other mechanisms of resistance such as antixenosis, antibiosis and tolerance needs to be studied to identity the best genotype among the 17 genotypes that could to be used for developing BPH resistant / tolerant variety with desirable yield and quality traits.

\section{Introduction}

Rice is a major staple food grain as well as a major source of carbohydrate and energy in the daily diet of an average Indian and demand for rice is likely to increase with an ever growing population of the country. More than 90 per cent of the world's rice is grown and consumed in Asia where 60 per cent of the global population lives. It is cultivated in about 154 million hectares annually which is equivalent to 11 per cent of the world's cultivated land. Rice is affected by more than two hundred insect pests of which about a dozen are economically important (Grist and Lever, 1969) and brown plant hopper is one among them.
The brown planthopper, is a phloem-sapsucking insect pest of rice (Sogawa, 1982). Both nymphs and adults suck the sap from the lower portion of the plant, which results in yellowing of leaves, reduction in tiller number, plant height, and finally results in unfilled grains. Feeding also causes reduction in chlorophyll and protein content of leaves followed by reduced rate of photosynthesis, in case of severe attack, it causes extensive plant mortality referred to as 'hopper burn' symptom. BPH also transmits rice grassy stunt virus (GSV) and ragged stunt virus (RSV) as a vector (Khush and Brar, 1991). In recent years, BPH infestations have increased across Asia, causing heavy yield losses in rice. As the popular rice varieties are susceptible to 
planthoppers, farmers are forced to depend solely on chemical pesticides for controlling this insect, which is expensive in terms of labour, cost and also pose environmental hazards. In addition, overuse of pesticides destroys the natural predators and leads to the development of insecticidal resistance, which results in pest resurgence. The best alternative for managing the pest is to follow integrated pest management using two important components viz., first adoption of resistant or tolerant variety and second use of insecticides with different modes of action from time to time.

\section{Materials and Methods}

A set of 39 elite rice genotypes (Table 1) found promising during initial field screening trials conducted at Rice Research Centre, ARI, Rajendranagar having desirable yield traits were selected for screening studies along with resistant check (PTB33, BM-17) and susceptible check (TN1). Screening of selected rice entries was carried out in polyhouse by following Standard Seed box Screening Technique (Heinrichs et al., 1985). The seeds of selected cultures were soaked in water for 24 hours by placing them in petri plates containing optimum quantity of water. The water was drained out after 24 hours and the soaked seeds were kept in the same petri plate for another 24 hours to allow proper germination. The pre-germinated seeds were planted in the plastic trays of size $(45 \times 35 \times$ $10 \mathrm{~cm}$ ) filled with fertilizer enriched puddled soil. The sown seeds were covered with thin layer of soil and watered as and when required.

First and second instar nymphs of BPH were released on 12-13 day old seedlings of the test entries by tapping heavily infested plants from oviposition cages on the screening trays, ensuring that each test seedling was infested with at least 6-8 nymphs. The screening trays with BPH nymphs were covered with mylar cages to prevent escape of the nymphs. The trays were rotated by $180^{\circ}$ at frequent intervals for attaining even reaction of plant response to BPH infestation and to avoid the susceptible germplasm seedlings showing quick reaction compared to resistant. All the test entries were replicated thrice. A maximum of 20 entries with PTB-33 (resistant check) at the centre and TN1 susceptible cultivar on either side of the tray was planted/tray. The position of 20 entries that were planted in each standard seed box were also randomized in three replications. A total of six such standard seed boxes were set up to evaluate the resistance response of 39 test entries.

The infested seedlings were monitored until the susceptible check (TN1) seedlings showed 90 per cent mortality. When more than 90 per cent plants of the susceptible check, TN1 were killed, the scoring was done based on 0-9 scale using Standard Evaluation System (SES) developed by the International Rice Research Institute (IRRI, 2014) as detailed in Table 2. After scoring as per Standard Evaluation System (SES) the SSST entries were categorized as described in the Table 3 (Jegadeeswaran et al., 2014).

\section{Results and Discussion}

Perusal of data (Table 2) revealed that, among 42 entries, two entries viz., PTB 33 and BM 71 with damage score of 3.0 were found to be resistant (R), while 17 entries recorded damage score ranging from 3.6-4.9 showing moderately resistant reaction. Among the moderately resistant entries, 2 entries viz., KNM 2305 and RNR 21571 registered damage score of3.6 while MTU 1010 and RNR 23079 showed 4.2 and 4.3 damage score, respectively. Similarly, 3 entries viz., MTU 1001, RNR 11718 and KNM 2307 exhibited damage score of 4.4 followed by JGL 24423 (DS 4.5) (Table 4). 
Table.1 Selected rice genotypes for mass screening against BPH following Standard Seed box Screening Technique (SSST)

\begin{tabular}{|c|c|c|c|c|c|}
\hline $\begin{array}{l}\text { S. } \\
\text { No. }\end{array}$ & $\begin{array}{l}\text { Rice } \\
\text { Genotypes }\end{array}$ & Parentage / Cross & $\begin{array}{l}\text { S. } \\
\text { No. }\end{array}$ & $\begin{array}{l}\text { Rice } \\
\text { Genotypes }\end{array}$ & Parentage / Cross \\
\hline 1 & BM 71 & Vajram/ Darrington & 22 & KNM 1638 & JGL $11727 \times$ JGL 17004 \\
\hline 2 & PTB 33 & $\begin{array}{l}\text { Pure line selection from land } \\
\text { race from Pattambi }\end{array}$ & 23 & KNM 3457 & JGL $18799 \times$ NLR 34449 \\
\hline 3 & KNM 2305 & JGL $11471 \times$ Himalaya 741 & 24 & RNR 26100 & Akshayadhan $\times$ RNR 2458 \\
\hline 4 & RNR1571 & $\begin{array}{l}\text { MTU } 1010 \times \text { JGL } \\
\text { 3855/MTU//1010/NLR } 34449\end{array}$ & 25 & RNR 26101 & Akshayadhan $\times$ RNR 2458 \\
\hline 5 & MTU 1010 & Krishnaveni/IR 64 & 26 & JGL 24332 & MTU $1010 \times$ NLR 34449 \\
\hline 6 & RNR 3079 & CR 1009/NLR145 & 27 & KNM 4058 & JGL $11470 \times$ GEB 35 \\
\hline 7 & MTU 1001 & Vajram/MTU 7014 & 28 & KPS 7558 & BM $71 \times$ NLR 34449 \\
\hline 8 & KNM 2307 & JGL $11727 \times$ JGL 17004 & 29 & JGL 25153 & JGL17653/RP 2421 \\
\hline 9 & RNR 1718 & MTU 1010/NLR 34449 & 30 & Sinnasivappu & - \\
\hline 10 & JGL 24423 & $\begin{array}{l}\text { MTU } 1010 \times \text { NLR } \\
34449 / M T U / 1010\end{array}$ & 31 & Sabita & 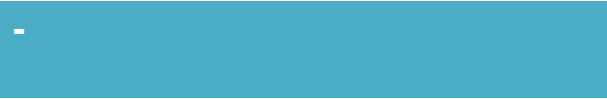 \\
\hline 11 & RNR 5838 & $\begin{array}{l}\text { Sumathi } \times \text { IR } 79216-141-1 \\
-3-3\end{array}$ & 32 & WGL 962 & $\begin{array}{l}\text { BPT 5204/GEB 24//PTB } \\
\text { 5204/Shathabdhi } \\
\end{array}$ \\
\hline 12 & RNR 0933 & Sagar samba $\times$ BM 71 & 33 & KPS 7988 & Akshayadhan $\times$ BM 71 \\
\hline 13 & RNR 6111 & MTU $1010 \times$ Raasi & 34 & RNR 26121 & RNR $17469 \times$ BVM 1 \\
\hline 14 & RNR 993/2 & $\begin{array}{l}2 \mathrm{~K} 3-339-7-5-1-3 \times \\
\text { JGL/1798 }\end{array}$ & 35 & KNM 4068 & $\begin{array}{l}\text { JGL } 3844 \times \text { IR 8222-851/ } \\
\text { MTU/1075 }\end{array}$ \\
\hline 15 & RNR 5792 & Bhadrakali × NSN 20894 & 36 & KNM 733 & MTU $1010 \times$ JGL 11470 \\
\hline 16 & IET 23993 & IR64/ Ady. Selection@ & 37 & RNR 23605 & Pusa $1121 \times$ BM 71 \\
\hline 17 & JGL 24527 & JGL $11727 \times$ RP 2421 & 38 & RNR 23563 & RNR $2458 \times$ BM 71 \\
\hline 18 & KNM 4073 & $\begin{array}{l}\text { JGL } 18047 \times \text { IR8222- } \\
851 / / \text { MTU1075 }\end{array}$ & 39 & RNR 23593 & Yamini $\times$ BM 71 \\
\hline 19 & RNR 3595 & Yamini $\times$ BM 71 & 40 & RNR 23646-2 & WGL $14 \times$ MTU 1081 \\
\hline 20 & RNR 3606 & Pusa $1121 \times$ BM 71 & 41 & RNR 26120 & $\begin{array}{l}\text { RNR } 17469 \times \\
\text { Tellahamsa//MTU/1010 }\end{array}$ \\
\hline 21 & RNR 3646-1 & WGL $14 \times$ MTU 1081 & 42 & TN1 & Dee-Geo-Wu-Gen/Tsai-yuan-chu \\
\hline
\end{tabular}

Table.2 Standard Evaluation System (SES) describing the damage score of plant based on its reaction to $\mathrm{BPH}$ incidence

\begin{tabular}{|l|}
\hline Plant state \\
\hline No damage \\
\hline Very slight damage \\
\hline Lower leaf wilted with two green upper leaves \\
\hline Two lower leaves wilted with one green upper leaf \\
\hline All three leaves wilted but stem still green \\
\hline
\end{tabular}
Damage Score

\begin{tabular}{|c|}
\hline $\mathbf{0}$ \\
\hline $\mathbf{1}$ \\
\hline $\mathbf{3}$ \\
\hline $\mathbf{5}$ \\
\hline $\mathbf{7}$ \\
\hline $\mathbf{9}$ \\
\hline
\end{tabular}


Table.3 Categorization of levels of resistance based on damage score

\begin{tabular}{|c|l|c|}
\hline S. No. & \multicolumn{1}{|c|}{ Reaction } & Damage score range \\
\hline 1 & Resistant (R) & $1.0-3.0$ \\
\hline 2 & Moderately Resistant (MR) & $3.1-5.0$ \\
\hline 3 & Moderately Susceptible (MS) & $5.1-7.0$ \\
\hline 4 & Susceptible (S) & $7.1-8.9$ \\
\hline 5 & Highly Susceptible (HS) & 9.0 \\
\hline
\end{tabular}

Table.4 Reaction of different rice cultures against BPH

\begin{tabular}{|c|c|c|c|c|c|c|c|}
\hline $\begin{array}{l}\text { S. } \\
\text { No. }\end{array}$ & $\begin{array}{c}\text { Rice } \\
\text { Genotype }\end{array}$ & $\begin{array}{l}\text { Mean Damage } \\
\text { Score } \pm \mathrm{SE}\end{array}$ & Reaction & S. No. & Rice Genotype & $\begin{array}{l}\text { Mean Damage } \\
\text { Score } \pm \text { SE }\end{array}$ & Reaction \\
\hline 1 & BM 71 & $1.3 \pm 0.835$ & $\mathrm{R}$ & 22 & RNR 23606 & $6.0 \pm 0.200$ & MS \\
\hline 2 & PTB 33 & $2.6 \pm 0.306$ & $\mathrm{R}$ & 23 & RNR 23646-1 & $6.0 \pm 0.200$ & MS \\
\hline 3 & KNM 2305 & $3.6 \pm 0.400$ & MR & 24 & KNM 1638 & $6.1 \pm 0.067$ & MS \\
\hline 4 & RNR 21571 & $3.6 \pm 0.400$ & MR & 25 & KNM 3457 & $6.6 \pm 0.133$ & MS \\
\hline 5 & MTU 1010 & $4.2 \pm 0.033$ & MR & 26 & RNR 26100 & $6.7 \pm 0.067$ & MS \\
\hline 6 & RNR 23079 & $4.3 \pm 0.291$ & MR & 27 & RNR 26101 & $6.8 \pm 0.000$ & MS \\
\hline 7 & MTU 1001 & $4.4 \pm 0.200$ & MR & 28 & JGL 24332 & $6.8 \pm 0.000$ & MS \\
\hline 8 & KNM 2307 & $4.4 \pm 0.333$ & MR & 29 & KNM 4058 & $6.8 \pm 0.067$ & MS \\
\hline 9 & RNR 11718 & $4.4 \pm 0.333$ & MR & 30 & KPS 7558 & $7.4 \pm 0.067$ & $\mathbf{S}$ \\
\hline 10 & JGL 24423 & $4.5 \pm 0.371$ & MR & 31 & JGL 25153 & $7.6 \pm 0.000$ & S \\
\hline 11 & RNR 25838 & $4.6 \pm 0.200$ & MR & 32 & WGL 962 & $7.6 \pm 0.000$ & $\mathbf{S}$ \\
\hline 12 & RNR 20933 & $4.6 \pm 0.231$ & MR & 33 & KPS 7988 & $8.3 \pm 0.467$ & $\mathbf{S}$ \\
\hline 13 & RNR 26111 & $4.7 \pm 0.176$ & MR & 34 & RNR 26121 & $9.0 \pm 0.000$ & $\overline{\text { HS }}$ \\
\hline 14 & SABITA & $4.7 \pm 0.176$ & MR & 35 & KNM 4068 & $9.0 \pm 0.000$ & $\overline{\mathrm{HS}}$ \\
\hline 15 & RNR 25993/2 & $4.8 \pm 0.000$ & MR & 36 & KNM 733 & $9.0 \pm 0.000$ & $\overline{\text { HS }}$ \\
\hline 16 & RNR 25792 & $4.8 \pm 0.067$ & MR & 37 & RNR 23605 & $9.0 \pm 0.000$ & HS \\
\hline 17 & SinnaSivappu & $4.8 \pm 0.067$ & MR & 38 & RNR 23563 & $9.0 \pm 0.000$ & $\overline{\mathrm{HS}}$ \\
\hline 18 & IET 23993 & $4.8 \pm 0.133$ & MR & 39 & RNR 23593 & $9.0 \pm 0.000$ & HS \\
\hline 19 & JGL 24527 & $5.0 \pm 0.000$ & MR & 40 & RNR 23646-2 & $9.0 \pm 0.000$ & HS \\
\hline 20 & KNM 4073 & $6.0 \pm 0.115$ & MS & 41 & RNR 26120 & $9.0 \pm 0.000$ & HS \\
\hline 21 & RNR 23595 & $6.0 \pm 0.115$ & MS & 42 & TN1 & $9.0 \pm 0.000$ & $\overline{\mathrm{HS}}$ \\
\hline
\end{tabular}


Further, two entries viz., RNR 25838 and RNR 20933 (DS 4.6), two entries viz., RNR 26111 and Sabita (DS 4.7), four entries viz., RNR 25993/2, RNR 25792, Sinnasivappu and IET 23993 (DS 4.8) and one entry viz., JGL 24527 registered damage score 5.0.

Among the remaining 23 entries, 10 entries were identified as moderately susceptible with damage score ranging from 5.1-7.0, while four entries were designated as susceptible which registered damage score ranging from 7.1 to 8.9. The remaining 9 entries including TN1 were found highly susceptible recording damage score of9.0. Several workers have reported PTB-33 as resistant to $\mathrm{BPH}$ which is being currently used as a resistant check in the screening studies (PrakashRao et al., 1976, Jegadeshwaran et al., 2014, Jena et al., 2014, Bhanu et al., 2014, Sarao et al., 2016 and Thamarai et al., 2017). Bhanu et al., 2014 reported BM 71 as highly resistant culture against BPHwhich, in accordance with the results obtained in the present study. The present investigation has identified 17 moderately resistant donors which could be useful in breeding for developing resistant varieties against BPH. However, further investigations on presence of other mechanisms of resistance such as antixenosis, antibiosis and tolerance needs to be studied to identity the best genotype among the 17 genotypes that could to be used for developing BPH resistant / tolerant variety with desirable yield and quality traits.

\section{Acknowledgement}

My first and earnest, acknowledgement must go to my guide, Dr. P. Rajanikanth and members N.R.G. Varma, M. Sreedhar for their scholastic guidance, unceasing interest, valuable knowledge, technical advice. I thank all my teachers, friends and university for their cooperation and help during the research programme.

\section{References}

Bhanu, K.V., Satyanarayana, P.V., Reddy, P.S and Reddy, A.V. 2014.MTU IJ 2067-4-1 (BM 71), A new brown planthopper resistant donor with high levels of antixenosis and antibiosis effects. International Journal of Innovative and Applied Research. 2 (12): 35- 41.

Grist, D.H and Lever, R.J.A.W. 1969.Pests of rice. Longmans, Green and Co.

Heinrichs, E.A., Medrano, F.D. and Rapusas, H.R. 1985. Genetic Evaluation for Insect Resistance in rice. In: Heinrichs E. A., Rapusas H and Medrano F. (eds) International Rice Research Institute, LosBanos, Philippines.1-356.

International Rice Research Institute. 2014. Standard evaluation system of rice (SES). $\quad 5^{\text {th }} \quad$ Edition. LosBanos; Phillipines.

Jegadeeswaran, M., Anandakumar, C.R and Maheswaran, M. 2014. Phenotypic screening of rice (Oryza sativa L.) varieties for brown planthopper [Nilaparvata lugens (Stal.)] resistance. Trends in Bioscience. 7 (16): $2257-$ 2266.

Jena, M., Panda, R.S., Sahu, R.K., Mukherjee, A.K and Dhua, U. 2014. Evaluation of rice genotypes for rice brown planthopper resistance through phenotypic reaction and genotypic analysis. Crop protection. 78: 119-126.

Khush, G.S and Brar, D.S. 1991. Genetics of resistance to insects in crop plants. Advances in Agronomy. 45:223274.Ltd., London. 520.

PrakashRao, P.S., Israel, P and Krishna, A.G. 1976. Brown planthopper attack in East Godavari. A.P., India. International Rice Research Newsletter. 1:17.

Sarao, P.S., Sahi, G.K., Neelum, K., Mangat, G.S., Patra, B.C and Singh, K. 2016. Donors for Resistance to Brown 
Planthopper Nilaparvata lugens (Stal.) from Wild Rice Species. Rice Science. 23 (4):1-6.

Sogawa, K. 1982. The rice brown planthopper: feeding physiology and host plant. Annual Review of Entomology. 27 (1):49-73.
Thamarai, M and Soundararajan, R.P. 2017. Reaction of Rice genotypes against specific population of brown planthopper, Nilaparvata lugens (Stal.). Annals of Plant Protection Science. 25 (1): 74-77.

\section{How to cite this article:}

Udayasree, M., P. Rajanikanth, N.R.G. Varma and Sreedhar, M. 2018. Screening of Selected Rice Genotypes for Their Resistance against Brown Planthopper, Nilaparvata lugens (Stal). Int.J.Curr.Microbiol.App.Sci. 7(11): 3138-3143. doi: https://doi.org/10.20546/ijcmas.2018.711.360 